Document downloaded from:

http://hdl.handle.net/10251/50369

This paper must be cited as:

Baeza, F.; Paya Bernabeu, JJ.; Galao, O.; Saval, J.; Garcés, P.; F.Baeza-Brotons (2014). Blending of industrial waste from different sources as partial substitution of portland cement in pastes and mortars. Construction and Building Materials. 66:645-653. doi:10.1016/j.conbuildmat.2014.05.089.

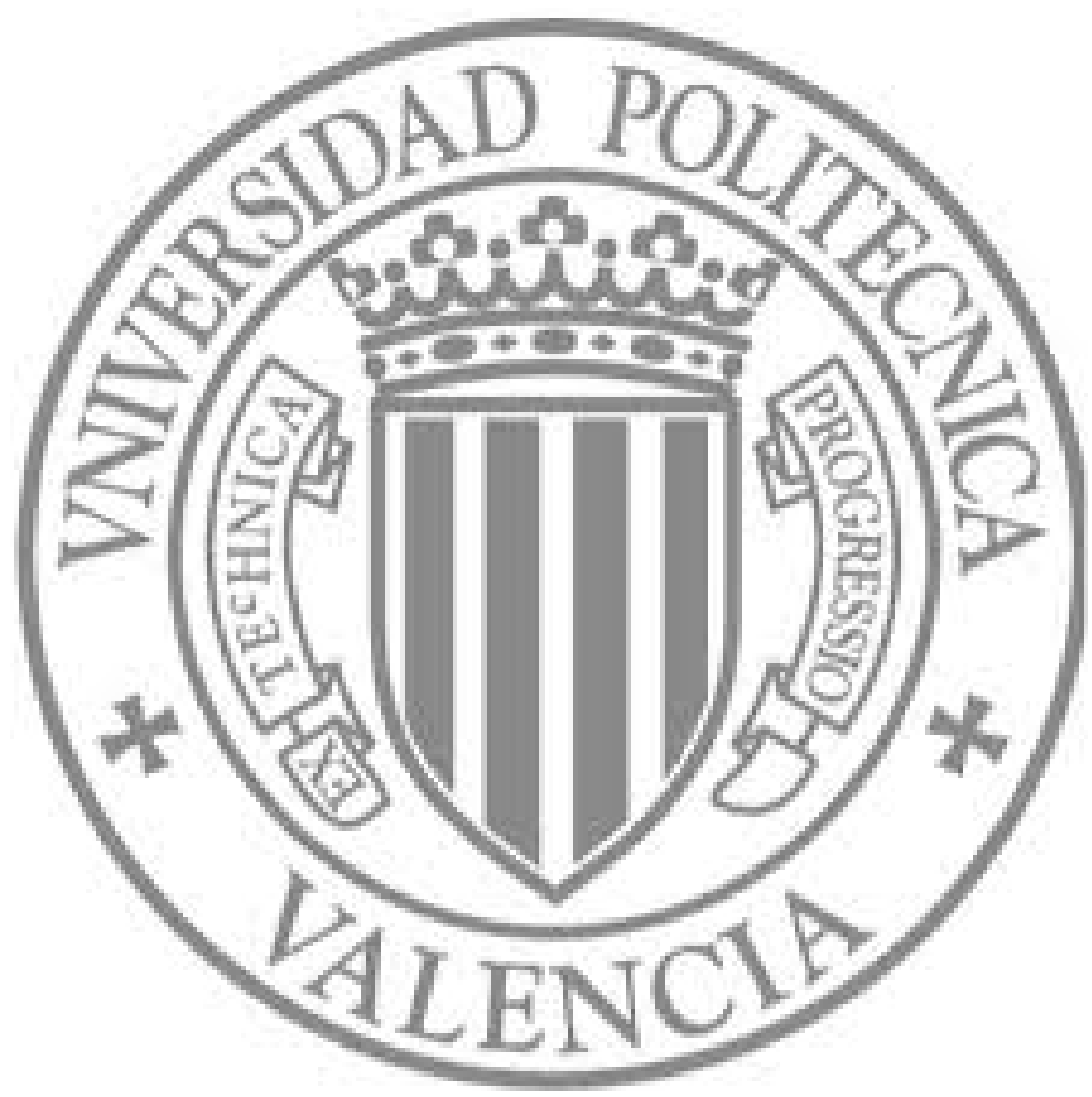

The final publication is available at

http://dx.doi.org/10.1016/j.conbuildmat.2014.05.089

Copyright Elsevier 


\title{
BLENDING OF INDUSTRIAL WASTE FROM DIFFERENT SOURCES AS PARTIAL SUSTITUTION OF PORTLAND CEMENT IN PASTES AND MORTARS
}

\author{
F. Baeza ${ }^{\mathrm{a}}$, J. Payá ${ }^{\mathrm{b}}$, O. Galao ${ }^{\mathrm{a}}$, J.M. Saval ${ }^{\mathrm{a}}$, P. Garcés ${ }^{\mathrm{a},{ }^{*}}$ \\ ${ }^{a}$ Department of Civil Engineering, Universitat d'Alacant, Carretera San Vicente del Raspeig \\ S/N, 03690 San Vicente del Raspeig, Alicante, Spain \\ ${ }^{\mathrm{b}}$ Institute of Concrete Science and Technology (ICITECH), Universitat Politècnica de València, \\ Camino de Vera S/N, 46022 Valencia, Spain \\ * Corresponding author. Tel.:+34 965903400-Ext 3324. \\ E-mail address: pedrogarces@ua.es (P. Garcés)
}

\begin{abstract}
Binary and ternary combinations of sewage sludge ash (SSA) with marble dust (MD), fly ash (FA) and rice husk ash (RHA) as replacement in Portland cement pastes, were assessed. Several tests were carried out at different curing ages: thermogravimetry, density, water absorption, ultrasonic pulse velocity and mechanical strengths. Pozzolanic effects of the mineral admixtures, densities similar to control sample and improved absorptions when combining waste materials were identified. In general, the compressive strength reaches or exceeds the cement strength class, and blending SSA, FA and RHA (30\% cement replacement) increase of strength by $9 \%$, compared to the control sample, was achieved.
\end{abstract}

Keywords: waste valorization, thermogravimetry, sewage sludge ash, marble dust, fly ash, rice husk ash.

\section{INTRODUCTION}

The construction industry is a great consumer of resources and materials, which makes it a sector with enormous potential for the use of waste materials generated by its own activities and those from other sectors. The reuse of such materials in cement based materials not only reduces pressure on landfill capacities but also reduces the need for raw material extraction [1].

Mineral admixtures, also known as supplementary cementitious materials, that can be added in blended Portland cements include limestone and certain pozzolanic materials such as coal fly ash and blast furnace slag [2]. This paper focuses on the study of the viability of using four different mineral additions generated in diverse industrial processes as cement substitutes in the dosage of cement pastes and mortars: a) ash from wastewater sewage treatment (SSA); b) fly ash from coal power plant (FA); c) marble dust (MD) generated from the cutting of large pieces of marble rocks; d) rice husk ash (RHA) from burning rice husk in a cogeneration power plant.

The use of mineral admixtures restarted in the 1950s, at that time focusing on their use in the manufacture of Portland cement or in the production of mortars and concrete. Since then, there has been an exponential increase in the use of mineral admixtures. Its real global production is difficult to find out. With FA, it has been reported that around 200 million tonnes are produced annually in India alone [3]. In the US and EU-15, the power plants that belong to the ACAA and ECOBA associations produce a total of at least 85 million tonnes. Another 35 million tonnes are supposed to be produced from the additional EU-12 countries. This is already a total of 320 million tonnes and that figure does not account for the by far world's largest coal burning country, China. An estimate for global annual FA production could be closer to 800 million tonnes. Global blast furnace slag production was estimated in 2002 to be around 150-180 million tonnes [4], and so it is likely to be significantly higher today. No reliable data for RHA and SF has been found. 
According to a specific study from the European Commission in 2010, the amount of sewage sludge from wastewater treatments produced in Spain was approximately 1.06 million tons of dry material [5]. The destination of this waste is: use as fertilizer $(65-80 \%)$, controlled landfill (8-20\%) or incineration to reduce its volume (generating sewage sludge ash, SSA). About 4$10 \%$ of the total amount of sludge is incinerated, but the trend is to increase this amount to 20$25 \%$, which is the average percentage of sewage sludge incinerated in Europe [5-7]. The problem with these residues after incineration, which justifies an intensive searching for alternatives to the landfill, is the presence of heavy metals in their composition, which turns it into a potential pollutant $[8,9]$.

Although marble dust (MD) is not a contaminant residue (98\% calcium carbonate), the uncontrolled dumping represents a problem in local scale, as it can cause environmental damages, primarily for visual impact and water pollution. Currently, the province of Alicante (Spain) produces and exports 70\% of domestic marble, being Spain the 2nd European producer and the 7th worldwide, generating near 500,000 tons of sludge (suspension of marble dust in water) in the region where the industry is concentrated, as a result of the cutting and polishing of natural stones [10].

Nowadays it is well known the effect of these residues individually, or combined in some cases, as substitutes for conventional binder composites:

- Previous work has shown that mortars containing SSA have good mechanical properties, and mortars with $10 \%$ cement substitution show insignificant differences in terms of steel reinforcement corrosion as compared to the control mortars $[11,12]$. This can be attributed to the pozzolanic activity of the SSA $[7,13]$, although recent research in reused materials has revealed that, compared with well-known pozzolanic materials, the pozzolanic activity of SSA is, at least, weak [14]. Furthermore, it must be noted a reduction in workability due to the irregular shape and roughness of the particles, which prevents its behavior as a solid lubricant, and the water absorption on the surface of the ash particles $[15,16]$.

- FA has been used for several decades as mineral addition, and its most notable features are: presence of cenospheres of particles, high content of vitreous silica $\left(\mathrm{SiO}_{2}\right)$ and alumina $\left(\mathrm{Al}_{2} \mathrm{O}_{3}\right)$ and pozzolanic activity at medium and long terms [17]. The incorporation of FA in Portland cement composites increases the workability and consistency of mortars and concrete [18].

- In cement/SSA/FA ternary systems for binder's manufacturing, the SSA provides an important pozzolanic activity, increasing the mechanical strength of mortars between 7 and 28 days. Likewise, SSA reduces the fluidity of mortars while the FA improves it $[19,20]$.

- Several publications show that the addition of MD in cementitious composites is effective in improving the cohesion of mixtures. It can replace up to $10 \%$ of sand without affecting the compressive strength, with a better mechanical performance as compared to the same limestone filler content, and providing lower water permeability [21,22]. In selfcompacting concrete, where the plastic viscosity of the concrete increase with the addition of MD sludge, and is corrected by adding specific superplasticizers, the concretes obtained are consistent with the standard requirements and their mechanical properties have improved, as a consequence of the increase of packaging, due to the incorporation of fine particles [23].

- In studies where RHA was used as a partial replacement of cement in mortar and concrete, the results for substitutions of $25 \%$ showed the same or better results as compared to conventional concrete [24]. Even with substitutions up to $30 \%$, improvements occurred in durability and consistency, not increasing the compressive strength at early ages, but improving it at older ages [25]. 
This paper gathers the effect on properties of standard pastes and mortars, replacing Portland cement by the mentioned waste materials, either individually, binary or ternary combinations, with special attention to SSA, expanding the knowledge about the exploitation of synergies generated in fresh and hardened mixtures.

\section{EXPERIMENTAL}

\subsection{Materials}

Mineral admixtures used in this work have the following origins: a) SSA has been supplied in bulk by the incinerator of the wastewater treatment plant of Pinedo in Valencia (Spain), where it was obtained from the discharge electrostatic precipitator of a fluidized bed incinerator working with a maximum temperature applied of $800^{\circ} \mathrm{C}, \mathrm{b}$ ) FA (class F) comes from the coal power plant of Andorra-Teruel (Spain) and it has been provided also in bulk; c) MD was obtained from a landfill located in the town of Novelda in the province of Alicante-Spain that collects the waste produced by numerous companies; d) RHA was collected in DACSA (Valencia, Spain) from an energy recovery plant which uses rice husks as fuel.

The Portland cement used was CEM II/B-L-32.5R type according to EN 197-1 [2] supplied by Cementval in bags of $25 \mathrm{~kg}$. The aggregate of mortar is CEN EN 196-1 (Normensand GMBH Beckum / Germany), supplied in bags with the required quantity (1350 g).

\subsection{Dosage}

Table 1 shows the dosage used in the different mixes. It can be seen that the mortar used as control is the one indicated in the Spanish Standard UNE-EN 196-1 [26]: mortars consisted of 3 parts sand, 1 part cement and 0.5 parts water. The water/binder ratio was kept constant for pastes and mortars. This means a water/(cement + addition) ratio of 0.5. Three series of each mixture were prepared: a) Series S1, with a substitution of $10 \%$ of Portland cement by each of the mineral residues used in this research. That is, in 1-S10 a 10\% of cement has been replaced by SSA, in 1-R10 by RHA, in 1-M10 by MD, and in 1-F10 by FA; b) Series S2, with a substitution of $20 \%$ of cement by binary combination of the previous mineral additions. That is, in 2-S20 a $20 \%$ of cement has been replaced by SSA, in 2-S10F10 with 10\% SSA and 10\% FA, etc; c) Series S3, with a substitution of $30 \%$ of cement by ternary combination.

This work intends to extend the possibilities for apprising a number of industrial wastes, paying greater attention to the SSA, so this residue appears as a component in all mixtures of series S2 and S3, except for the one identified as "2-M10F10". On the other hand, besides realizing comparisons with the control samples "C" (no additions), the series composed by the mixtures identified as "1-S10", "2-S20" and "3-S30", whose only addition is SSA, will be used also as references for comparisons.

Table 1. Pastes and mortars dosages, in grams and percentage.

\begin{tabular}{|c|c|c|c|c|c|c|c|c|c|c|c|c|c|c|}
\hline \multirow[b]{2}{*}{ Series } & \multirow{2}{*}{$\begin{array}{c}\text { Reference } \\
\text { sample }\end{array}$} & \multicolumn{6}{|c|}{ Pastes } & \multicolumn{7}{|c|}{ Mortars } \\
\hline & & Cem. & & dition & $\begin{array}{c}\text { Addition } \\
\quad 2\end{array}$ & $\begin{array}{c}\text { Addition } \\
\mathbf{3}\end{array}$ & Water & Sand & Cem. & & $\begin{array}{l}\text { ition } \\
1\end{array}$ & $\begin{array}{c}\text { Addition } \\
\quad 2\end{array}$ & $\begin{array}{c}\text { Addition } \\
\mathbf{3}\end{array}$ & Water \\
\hline & $\mathrm{C}$ & 100 & & & & & 50 & 1350 & 450 & & & & & 225 \\
\hline \multirow{4}{*}{ S1 } & $1-\mathrm{S} 10$ & 90 & 10 & $10 \%$ & & & 50 & 1350 & 405 & 45 & $10 \%$ & & & 225 \\
\hline & 1-R10 & 90 & 10 & $10 \%$ & & & 50 & 1350 & 405 & 45 & $10 \%$ & & & 225 \\
\hline & 1-M10 & 90 & 10 & $10 \%$ & & & 50 & 1350 & 405 & 45 & $10 \%$ & & & 225 \\
\hline & 1-F10 & 90 & 10 & $10 \%$ & & & 50 & 1350 & 405 & 45 & $10 \%$ & & & 225 \\
\hline S2 & 2-S20 & 80 & 20 & $20 \%$ & & & 50 & 1350 & 360 & 90 & $20 \%$ & & & 225 \\
\hline
\end{tabular}




\begin{tabular}{|c|c|c|c|c|c|c|c|c|c|c|c|c|c|c|c|c|}
\hline & 2-S10/F10 & 80 & 10 & $10 \%$ & 10 & $10 \%$ & & 50 & 1350 & 360 & 45 & $10 \%$ & 45 & $10 \%$ & & 225 \\
\hline & 2-S10/M10 & 80 & 10 & $10 \%$ & 10 & $10 \%$ & & 50 & 1350 & 360 & 45 & $10 \%$ & 45 & $10 \%$ & & 225 \\
\hline & 2-M10/F10 & 80 & 10 & $10 \%$ & 10 & $10 \%$ & & 50 & 1350 & 360 & 45 & $10 \%$ & 45 & $10 \%$ & & 225 \\
\hline & 2-S10/R10 & 80 & 10 & $10 \%$ & 10 & $10 \%$ & & 50 & 1350 & 360 & 45 & $10 \%$ & 45 & $10 \%$ & & 225 \\
\hline \multirow{3}{*}{ S3 } & $3-S 30$ & 70 & 30 & $30 \%$ & & & & 50 & 1350 & 315 & 135 & $30 \%$ & & & & 225 \\
\hline & 3-S10/F10/R10 & 70 & 10 & $10 \%$ & 10 & $10 \%$ & $10 \quad 10 \%$ & 50 & 1350 & 315 & 45 & $10 \%$ & 45 & $10 \%$ & $45 \quad 10 \%$ & 225 \\
\hline & 3-S20/R10 & 70 & 20 & $20 \%$ & 10 & $10 \%$ & & 50 & 1350 & 315 & 90 & $20 \%$ & 45 & $10 \%$ & & 225 \\
\hline
\end{tabular}

\subsection{Procedure on mineral additions: $\mathrm{X}$-ray fluorescence analysis}

In order to provide information about the chemical composition of the four residues used in this work as mineral additions, the X-ray fluorescence technique (XRF) was applied. The equipment used to carry out the technique was a sequential X-ray spectrometer (Philips Magix Pro) equipped with rhodium tube and beryllium window.

\subsection{Procedure on pastes - Thermogravimetry}

Thermogravimetry (TG) tests were carried out in order to study the hydration of pastes. For this purpose, 3 paste samples of each mixture were made, one for each curing age $(7,28$ and 90 days). PVC moulds with circular section, diameter of $3 \mathrm{~cm}$ and thickness of $1 \mathrm{~cm}$ were used. The components were dry mixed as a previous step to manual mixing. Each set of samples was held in the mould over a porcelain surface, covered with plastic wrap to prevent carbonation (which could invalidate future measurements of $\mathrm{CH}$ by TGA since $\mathrm{CH}+\mathrm{CO}_{2} \rightarrow \mathrm{CC}$ ), and stored in a humidity chamber $\left(20^{\circ} \mathrm{C}\right.$ and $\left.90 \% \mathrm{RH}\right)$ until the TG tests were carried out.

After reaching the curing age required for each case, half of the sample was separated and conditioned following the next procedure: 1) grinding in agate mortar, 2) acetone washing with suction by a vacuum pump to remove all liquids, 3) sieving in a normalized $100 \mu \mathrm{m}$ mesh, 4) drying in oven at $50{ }^{\circ} \mathrm{C}$ for 20 minutes. To carry out the TG test, a Netzsch-TG-209F3 thermobalance with an open ceramic (alumina) crucible of $85 \mu \mathrm{L}$ was used. The test was conducted in a dry nitrogen atmosphere at $75 \mathrm{~mL} / \mathrm{min}$ gas flow, with a heating rate of $10 \mathrm{~K} / \mathrm{min}$ in the temperature range between 35 and $600{ }^{\circ} \mathrm{C}$.

The analyzed results were obtained from the TG curves and their corresponding derivative curves (DTG or weight loss rate over time). In almost all of them it can be observed, with greater or lesser clarity, several peaks attributed to various hydration products [27] in two different regions, as shown in Figure 1.

- First region: between $75-200{ }^{\circ} \mathrm{C}$. One peak corresponding to the dehydration of the calcium-silicate-hydrates $(\mathrm{C}-\mathrm{S}-\mathrm{H})$ and ettringite $(\mathrm{AFt})$; and close to $150{ }^{\circ} \mathrm{C}$, a smaller peak corresponding to the dehydration of calcium-aluminates-hydrates (C-A-H) and calciumaluminosilicate-hydrates (C-A-S-H). An overlapping of the different thermogravimetric events can be observed in this region. 


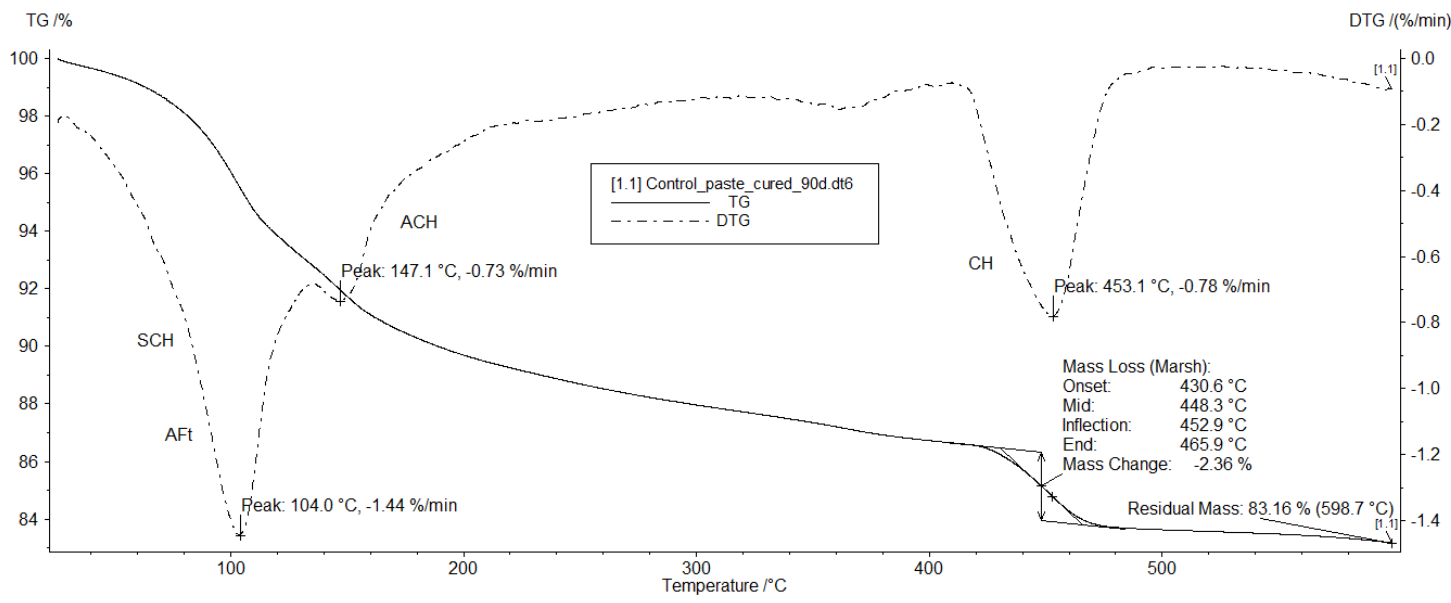

Figure 1. TG and DTG curves. Example of control paste cured for 90 days.

- Second region: $400^{\circ} \mathrm{C}-500^{\circ} \mathrm{C}$. The peak due to dehydroxylation of portlandite $(\mathrm{CH})$ formed during cement hydration can be observed.

The results section of this paper is focused on the analysis of the second region $(\mathrm{CH})$, which helps to determine the pozzolanic activity of the waste material in the cement mixture when it is used either individually or combined. The contents of all the tables in section 3.2 are the following:

a) Weight loss rate related to portlandite $\left(W_{C H}\right)$ obtained from TG curve;

b) Percentage of portlandite $(\mathrm{CH})$ obtained according to the expression:

$$
\text { Equation 1: } \% C H=\frac{W_{C H}(\%) * 74}{18}
$$

and which is based on the reaction indicated in Equation 2, where every $18 \mathrm{mg}$ of water that is lost within the temperature range that matches to the endothermic $\mathrm{CH}$ decomposition peak in TGA analysis corresponds to $74 \mathrm{mg}$ of $\mathrm{CH}$ originally present.

$$
\begin{array}{rl}
\text { Equation 2: } \mathrm{Ca}(\mathrm{OH})_{2} & \rightarrow \mathrm{CaO}+\mathrm{H}_{2} \mathrm{O} \\
74 \mathrm{~g} / \mathrm{mol} & 56 \mathrm{~g} / \mathrm{mol} \quad 18 \mathrm{~g} / \mathrm{mol}
\end{array}
$$

c) Percentage of fixed portlandite (FP) by the mineral addition, which is affected by the proportion of Portland cement and must be considered in the calculation. Therefore, this parameter is calculated using the following equation [27]:

$$
\text { Equation 3: } \% F P=\frac{\left[(C H)_{\left.c^{*}(1-S)\right]-(C H)_{i}}\right.}{\left[(C H)_{c} *(1-S)\right]} * 100
$$

where, for the same curing age $(\mathrm{CH})_{c}$ is the percentage of portlandite present in the control paste; $(\mathrm{CH})_{i}$ is the percentage of portlandite in each paste (involving one or more mineral additions) and $S$ is the proportion (per unit mass of binder) of the residue or residues used as cement replacement materials (if $10 \%$ of Portland cement is replaced, (1-S) is equal to 0.9 ; for $20 \%,(1-S)=0.8$; and for $30 \%(1-S)=0.7)$.

\subsection{Procedure on mortars}


Three prismatic samples per mixture with dimensions of 40x40x $160 \mathrm{~mm}^{3}$ were made for testing at curing ages of 28 and 90 days. Fresh samples were mechanically mixed, and after that a test of consistence of fresh mortar by flow table was made (according to UNE-EN 1015-3 [28] as a complementary datum required by the Standard that regulates the density [29]), and finally compacted. Compression strength tests were performed after 28 and 90 days of curing time. All the procedure was carried out in accordance to the Spanish Standard UNE-EN 196-1 [26], with the exception that all samples were kept after being demoulded in a humidity chamber $\left(20{ }^{\circ} \mathrm{C}\right.$ and $90 \% \mathrm{RH})$ until the tests were performed. A multi-test Suzpecar MEM-101-10A was the equipment used for this procedure.

The ultrasonic pulse velocity (Upv) was measured with a Steinkamp BP-5 machine on three specimens with 90 days of curing age, using the direct measurement method (on the longitudinal axis).

Compressive strength tests were carried out on samples with 90 days of curing age. The undamaged portions resulting from the compression test were reserved for density and absorption tests [30]; according to UNE-EN 1015-10 [29,31] obtaining the following parameters: 1) dry mass by oven drying until constant mass; 2) mass saturated in water until constant mass, 3) mass in hydrostatic underwater weighing. For this procedure, a MettlerToledo XS 4035 weighing scale was used.

\section{RESULTS AND DISCUSSION}

\subsection{Additions}

Table 2 shows the results of the four mineral admixtures used: oxide percentages were obtained by means of XRF, LOI percentages were obtained by loss on ignition tests and mean particle sizes were obtained by means of a laser diffraction analyzer. It can be observed that the SSA has a considerable content of $\mathrm{SiO}_{2}(16.98 \%)$ and $\mathrm{Al}_{2} \mathrm{O}_{3}(9.48 \%)$. This means that it could be considered as an active mineral addition on Portland cement based composites. The content of $\mathrm{CaO}, \mathrm{SO}_{3}, \mathrm{P}_{2} \mathrm{O}_{5}$ and $\mathrm{Fe}_{2} \mathrm{O}_{3}$ are also noticeable. The FA has a high content of silica (39.20\%) and a very high content of alumina $(27.31 \%)$, much higher than SSA. It could be defined as a pozzolanic mineral admixture and be classified as a type $\mathrm{F}$ fly ash (according to ASTM C618). Its content of $\mathrm{Fe}_{2} \mathrm{O}_{3}(16.79 \%)$ is also remarkable. The MD is essentially made of $\mathrm{CaO}(63.74 \%)$; therefore it is expected to behave as an inert mineral residue. Finally, the RHA is composed primarily of $\mathrm{SiO}_{2}(82.37 \%)$, thus it is a candidate for being used as a siliceous pozzolanic addition.

Table 2 . Oxide concentrations ( $\%$ by weight), LOI ( $\%$ by weight) and mean particle sizes $(\mu \mathrm{m})$ for different admixtures used. (ND: not determined).

\begin{tabular}{|c|c|c|c|c|}
\hline Oxide & $S S A$ & $F A$ & $M D$ & $R H A$ \\
\hline $\mathrm{Na}_{2} \mathrm{O}$ & 0.92 & 0.18 & 0.39 & 0.09 \\
\hline $\mathrm{MgO}$ & 3.17 & 1.13 & 6.85 & 0.68 \\
\hline $\mathrm{Al}_{2} \mathrm{O}_{3}$ & 9.48 & 27.31 & 1.38 & 0.44 \\
\hline $\mathrm{SiO}_{2}$ & 16.98 & 39.20 & 3.74 & 82.37 \\
\hline $\mathrm{P}_{2} \mathrm{O}_{5}$ & 14.01 & 0.69 & 0.09 & 0.96 \\
\hline $\mathrm{SO}_{3}$ & 8.80 & 1.63 & 1.26 & 0.33 \\
\hline $\mathrm{K}_{2} \mathrm{O}$ & 1.26 & 1.37 & 0.30 & 3.54 \\
\hline $\mathrm{CaO}$ & 29.73 & 5.94 & 63.74 & 1.24 \\
\hline $\mathrm{TiO}_{2}$ & 0.90 & 0.96 & - & 0.02 \\
\hline $\mathrm{Fe}_{2} \mathrm{O}_{3}$ & 8.38 & 16.79 & 0.35 & 0.16 \\
\hline $\mathrm{ZnO}$ & 0.31 & 0.03 & - & 0.01 \\
\hline $\mathrm{SrO}$ & 0.25 & 0.12 & 0.04 & 0.01 \\
\hline
\end{tabular}




\begin{tabular}{|c|c|c|c|c|}
\hline $\mathrm{Cl}$ & 0.15 & - & 0.13 & 0.28 \\
\hline ND & 0.66 & 0.27 & 0 & 0.16 \\
\hline LOI & 4.55 & 3.43 & 20.99 & 8.71 \\
\hline Total & $\mathbf{9 9 . 5 5}$ & $\mathbf{9 9 . 0 6}$ & $\mathbf{9 9 . 2 5}$ & $\mathbf{9 9 . 0 2}$ \\
\hline $\begin{array}{c}\text { Mean } \\
\text { particle } \\
\text { size }\end{array}$ & 16.667 & 7.843 & 4.953 & 8.160 \\
\hline
\end{tabular}

\subsection{Thermogravimetry}

Control samples (C-7, C-28 and C-90) let to evaluate the amount of portlandite generated in the hydration of Portland cement. One can observe in Table 3 that the amount of $\mathrm{CH}$ was very high at early ages (9.78\% at 7 days), and it was increasing moderately for longer curing times. By blending, when a part of Portland cement is replaced by a pozzolanic addition, the available amount of portlandite will be proportionally diminished. Then, when the substitution percentages are higher, the available $\mathrm{CH}$ percentages for pozzolanic reaction are lower, which is partly consistent with lower Portland cement contents. Thus, when the calculated percentage of fixed portlandite (FP) is positive, it means that pozzolanic reaction was significant; whereas if FP is negative or equal to zero, it means that pozzolanic reaction did not take place. In almost all the tests carried out (see Table 3), FP values were positive, and they increment as the curing time increases, which indicates that there is a progress of the pozzolanic effect. In some cases, FP positive values are observed at early ages, as shown by the data taken at 7 days. The fact of using different mineral admixtures with varying degrees of pozzolanic activity for the same percentage of substitution implies changes among the different pastes.

It might be interesting to analyze carefully the behavior of series $\mathrm{S} 1$ (10\% of cement replacement-Table 3), as the results obtained with individual residues would provide information about the contribution of each of them in the series S2 and S3.

Table 3. Paste - Series S1. TG results for mixes with curing ages of 7, 28 and 90 days. (n.a.: not applicable).

\begin{tabular}{|l|ccc|}
\hline Reference sample & $\begin{array}{c}W_{C H} \\
(\%)\end{array}$ & $\begin{array}{c}C H \\
(\%)\end{array}$ & $\begin{array}{c}F P \\
(\%)\end{array}$ \\
\hline C-7 & 2.38 & 9.78 & n.a. \\
C-28 & 2.43 & 9.99 & n.a. \\
C-90 & 2.50 & 10.28 & n.a. \\
\hline 1-S10-7 & 1.91 & 7.85 & 10.83 \\
1-S10-28 & 1.87 & 7.69 & 14.49 \\
1-S10-90 & 1.97 & 8.10 & 12.44 \\
\hline 1-R10-7 & 2.05 & 8.43 & 4.30 \\
1-R10-28 & 1.88 & 7.73 & 14.04 \\
1-R10-90 & 1.48 & 6.08 & 34.22 \\
\hline 1-M10-7 & 2.18 & 8,96 & -1.77 \\
1-M10-28 & 2.30 & 9.46 & -5.17 \\
1-M10-90 & 2.28 & 9.37 & -1.33 \\
\hline 1-F10-7 & 2.19 & 9.00 & -2.24 \\
1-F10-28 & 2.19 & 9.00 & -0.14 \\
1-F10-90 & 2.02 & 8.30 & 10.22 \\
\hline
\end{tabular}

Focusing on pastes cured for 90 days, the percentage of $\mathrm{CH}$ in paste 1-M10 is similar to the control sample (10.28\%) but lower $(9.37 \%)$ due to its inertness and lower cement content. The paste 1-R10 showed a much lower percentage of $\mathrm{CH}(6.08 \%)$ and the pastes 1-S10 and 1-F10 showed similar percentage of $\mathrm{CH}$ ( 8.10 and $8.30 \%$, respectively). These differences are 
attributed to the differences in the pozzolanic activity of the different admixtures when fixing portlandite, as mentioned above.



Figure 2. Paste - Series S1 (10\% replacement). Percentage of fixed portlandite (FP) in pastes with curing ages of 7, 28 and 90 days.

The previous observations about portlandite can be complemented with the results obtained from the percentages of the fixed portlandite by the mineral admixtures used, both parameters related through Equation 3, for curing ages of 7, 28 and 90 days (Figure 2). It may be noticed in the series $\mathrm{S} 1$ that mixture 1-R10 shows the lowest percentage of $\mathrm{CH}$ and the highest percentage of fixed portlandite at 28 and 90 days. Therefore, it can be established that this is the most pozzolanic mineral addition of the ones studied, which is consistent with the silica content in this residue. The pozzolanic reaction for RHA progress with curing time, and it is relevant that FP is increasing from $4.30 \%$ at 7 days to $34.22 \%$ for 90 days. On the contrary, FP values for pastes containing MD are negative, demonstrating that there was no pozzolanic behavior and suggesting that activates slightly the hydration of Portland cement. Finally, SSA and FA showed similar FP values for 90 days (12.44 y $10.2 \%$ respectively). However, their behavior with curing time became very different. Thus, SSA showed high reactivity for early ages, yielding FP of $10.83 \%$ after 7 days. On the contrary, in FA pastes no evidences of pozzolanic reactivity were observed at 7 and 28 days (FP values were slightly negative), and for 90 days positive FP value was obtained, which agree the long-term reactivity for this type of pozzolan.

For the series S2 (20\% of cement substitution), TG data are summarized in Table 4. For pastes cured during 90 days, it can be stated in terms of portlandite percentage that the individual contribution of the mineral additions, annotated in the series S1, is reflected quite clearly when performing binary combinations of them with the cement in this series: SSA and FA showed a similar behavior, and the combination of them in the pair 2-S20 and 2-S10F10, as well as in the pair 2-S10M10 and 2-M10F10, are similar in this case, with average percentages of $\mathrm{CH}$ of $5.3 \%$ in the first case and of $6.7 \%$ in the second case. Thus, for the blends containing MD, the portlandite fixation is lower. The paste 2-S10R10 showed the lowest percentage of $\mathrm{CH}(1.77 \%)$ due to its content of RHA, yielding portlandite fixation percentages of $78.50 \%$.

For SSA/FA and SSA/MD blended pastes (Table 4), FP values were very similar for early curing ages: 8.09 and $9.66 \%$ respectively. However, due to long-term pozzolanic reactivity of FA, SSA/FA blend yielded 31\%, whereas SSA-MD increased only to $19.50 \%$ after 90 days. The highest percentage of fixed portlandite for the three ages studied was found for paste 2-S10R10, with a remarkable increase respect to paste 2-S20. This means that the combination of SSA + RHA may be of interest in order to develop stronger composites, although logically with a smaller final content of portlandite. 
Table 4. Paste - Series S2. TG results for mixtures with curing ages of 7, 28 and 90 days. (n.a.: not applicable).

\begin{tabular}{|l|ccc|}
\hline \multicolumn{1}{|c|}{$\begin{array}{c}\text { Reference } \\
\text { sample }\end{array}$} & $\begin{array}{c}W_{C H} \\
(\%)\end{array}$ & $\begin{array}{c}C H \\
(\%)\end{array}$ & $\begin{array}{c}F P \\
(\%)\end{array}$ \\
\hline C-7 & 2.38 & 9.78 & n.a. \\
C-28 & 2.43 & 9.99 & n.a. \\
C-90 & 2.50 & 10.28 & n.a. \\
\hline 2-S20-7 & 1.37 & 5.63 & 28.05 \\
2-S20-28 & 1.35 & 5.55 & 30.56 \\
2-S20-90 & 1.18 & 4.85 & 41.00 \\
\hline 2-S10F10-7 & 1.75 & 7.19 & 8.09 \\
2-S10F10-28 & 1.65 & 6.78 & 15.12 \\
2-S10F10-90 & 1.38 & 5.67 & 31.00 \\
\hline 2-S10M10-7 & 1.72 & 7.07 & 9.66 \\
2-S10M10-28 & 1.66 & 6.82 & 14.61 \\
2-S10M10-90 & 1.61 & 6.62 & 19.50 \\
\hline 2-M10F10-7 & 1.94 & 7.98 & -1.89 \\
2-M10F10-28 & 1.92 & 7.89 & 1.23 \\
2-M10F10-90 & 1.64 & 6.74 & 18.00 \\
\hline 2-S10R10-7 & 1.23 & 5.06 & 35.40 \\
2-S10R10-28 & 0.85 & 3.49 & 56.28 \\
2-S10R10-90 & 0.43 & 1.77 & 78.50 \\
\hline
\end{tabular}

The content of $\mathrm{CH}$ observed for series S3 (30\% substitution - Table 5) showed a similar trend to those of series S1 and S2. In the three mixtures (3-S30, 3-S10F10R10 and 3-S20R10), the CH percentage decreases with increasing curing time, in contrast to the control sample. Also $\mathrm{CH}$ percentage values are well below the reference value. This is due in part to the smaller amount of Portland cement in the mixtures (30\% lower than in the control mixtures) and to the reactivity of mineral admixtures.

Table 5. Paste - Series S3. TG results for mixtures with curing ages of 7, 28 and 90 days. (n.a.: not applicable).

\begin{tabular}{|l|ccc|}
\hline \multicolumn{1}{|c|}{$\begin{array}{c}\text { Reference } \\
\text { Sample }\end{array}$} & $\begin{array}{c}W_{C H} \\
(\%)\end{array}$ & $\begin{array}{c}C H \\
(\%)\end{array}$ & $\begin{array}{c}F P \\
(\%)\end{array}$ \\
\hline C-7 & 2.38 & 9.78 & n.a. \\
C-28 & 2.43 & 9.99 & n.a. \\
C-90 & 2.50 & 10.28 & n.a. \\
\hline 3-S30-7 & 1.14 & 4.69 & 31.57 \\
3-S30-28 & 1.06 & 4.36 & 37.68 \\
3-S30-90 & 1.04 & 4.28 & 40.57 \\
\hline 3-S10F10R10-7 & 1.30 & 5.34 & 21.97 \\
3-S10F10R10-28 & 0.85 & 3.49 & 50.03 \\
3-S10F10R10-90 & 0.40 & 1.64 & 77.14 \\
\hline 3-S20R10-7 & 1.01 & 4.15 & 39.38 \\
3-S20R10-28 & 0.63 & 2.59 & 62.96 \\
3-S20R10-90 & 0.29 & 1.19 & 83.43 \\
\hline
\end{tabular}

For $30 \%$ cement replacement, it was observed that SSA reacts also at early ages, yielding a paste with 4.69 of $\mathrm{CH}$ after 7 days of curing. This value decreased slightly for 28 and 90 days of curing which confirms the typical pozzolanic behavior for SSA. At earliest curing age, 7 days, sample containing the ternary combination SSA/FA/RHA yielded a paste with highest $\mathrm{CH}$ content if compared sample 3-S30. This behavior revealed that the presence of FA in $10 \%$ 
diminished the global pozzolanic reactivity at early age, despite the presence of RHA. However, when a mixture of SSA/RHA was used (in 20\%/10\% replacements) better pozzolanic behavior was observed: $4.15 \%$ was the $\mathrm{CH}$ content, lower than those found for 3-S30. The ternary blend SSA/FA/RHA yielded good behavior for longest curing time: after 90 days of curing, the remaining $\mathrm{CH}$ was $1.64 \%$, which indicates that FA played an important role. Finally, for binary mixture SSA/RHA the lowest $\mathrm{CH}$ content was found (1.19\%), revealing that this mixtures was the most reactive from the pozzolanic point of view.

It can be observed (Table 5) that the combination of waste materials in substitutions of $30 \%$ at 28 and 90 days increases the fixed portlandite percentage if compared to the mixture 3-S30. This fact implies that the incorporation of RHA to the mixtures is of great interest for the development of the pozzolanic reaction. Furthermore, it is possible to add FA to these ternary admixtures to develop a highly reactive addition-mix.

Comparing the influence of each waste material individually on the overall behavior of the three series, the following considerations can be set:

- The pastes containing FA show higher increments of fixed portlandite in pastes cured for 90 days. This agrees to the higher reactivity of the FA at those ages; this effect can be of interest for the gradual development of the pozzolanic activity in composites with SSA and with SSA+RHA.

- In pastes containing MD, this admixture behaves, as expected, as an inert admixture, not showing any pozzolanic activity.

- The mixtures that include RHA in their composition show highest percentages of fixed portlandite (around $80 \%$ at 90 days in $20 \%$ and $30 \%$ replacing percentages).

\subsection{Density and water absorption in mortars}

Table 6 shows the average values of the representative mortar samples from each set, cured for 90 days. In terms of density, there is no big difference among the mixtures in relative values, but the following observations can be made:

- For all the mixtures, this parameter is lower than in the control sample (all the waste materials have lower densities than cement), but in almost all of them it is higher than the $97 \%$ of the control sample.

- As expected in the reference series (mixtures 1-S10, 2-S20 and 3-S30) there is a reduction of this parameter when the proportion of SSA is increased. Just as this waste material, the mortar generated has the lowest density of all. Any binary or ternary combination of waste exceeds the density of the mortar with only SSA in its series, except for the mix 2-S10M10.

Table 6. Consistency (C) of fresh mortar, Dry mass density (Dmd) and water absorption (Abs) for mortar specimens cured for 90 days. ( $\sigma$ : standard deviation, rel: relative value respect to control sample).

\begin{tabular}{|c|l|c|ccc|ccc|}
\hline \multirow{3}{*}{ Series } & Reference sample & $\begin{array}{c}C \\
(\mathrm{~cm})\end{array}$ & $\begin{array}{c}\text { Dmd } \\
\left(\mathrm{Kg} / \mathrm{m}^{3}\right)\end{array}$ & $\begin{array}{c}\sigma \\
\left(\mathrm{Kg} / \mathrm{m}^{3}\right)\end{array}$ & $\begin{array}{c}\text { Dmd } \\
\text { rel. }\end{array}$ & $\begin{array}{c}\text { Abs } \\
(\%)\end{array}$ & $\begin{array}{c}\sigma \\
(\%)\end{array}$ & $\begin{array}{c}\text { Abs rel. } \\
(\%)\end{array}$ \\
\hline \multirow{3}{*}{$S 1$} & Control & 17.1 & 2094 & 10.40 & 100 & 8.3 & 0.13 & 100 \\
\hline \multirow{3}{*}{$S 1-\mathrm{S} 10$} & 14.3 & 2034 & 6.10 & 97.1 & 9.7 & 0.51 & 117.6 \\
\cline { 2 - 10 } & $1-\mathrm{R} 10$ & 15.9 & 2069 & 4.89 & 98.8 & 9.0 & 0.15 & 108.8 \\
\cline { 2 - 10 } & $1-\mathrm{M} 10$ & 17.2 & 2046 & 4.34 & 97.7 & 9.3 & 0.08 & 112.8 \\
\cline { 2 - 10 } & $1-\mathrm{F} 10$ & 17.5 & 2092 & 8.29 & 99.9 & 8.7 & 0.18 & 104.7 \\
\hline
\end{tabular}




\begin{tabular}{|c|l|c|ccc|ccc|}
\hline \multirow{3}{*}{ Series } & Reference sample & $\begin{array}{c}C \\
(\mathrm{~cm})\end{array}$ & $\begin{array}{c}\text { Dmd } \\
\left(\mathrm{Kg} / \mathrm{m}^{3}\right)\end{array}$ & $\begin{array}{c}\sigma \\
\left(\mathrm{Kg} / \mathrm{m}^{3}\right)\end{array}$ & $\begin{array}{c}\text { Dmd } \\
\text { rel. } \\
(\%)\end{array}$ & $\begin{array}{c}\text { Abs } \\
(\%)\end{array}$ & $\begin{array}{c}\sigma \\
(\%)\end{array}$ & $\begin{array}{c}\text { Abs rel. } \\
(\%)\end{array}$ \\
\hline \multirow{5}{*}{$S 2$} & 12.9 & 2032 & 3.87 & 97.0 & 9.5 & 0.10 & 114.6 \\
\cline { 2 - 9 } & 2-S20 & 15.1 & 2045 & 1.74 & 97.7 & 9.3 & 0.12 & 112.4 \\
\cline { 2 - 9 } & 2-S10F10 & 14.7 & 2016 & 3.71 & 96.3 & 10.0 & 0.11 & 121.3 \\
\cline { 2 - 9 } & 2-S10M10 & 17.8 & 2056 & 4.39 & 98.2 & 9.5 & 0.10 & 114.7 \\
\cline { 2 - 9 } & 2-S10R10 & 14.1 & 2037 & 1.11 & 97.3 & 10.2 & 0.01 & 123.7 \\
\hline \multirow{3}{*}{$S 3$} & 3-S30 & 11.0 & 1964 & 3.62 & 93.8 & 11.3 & 0.43 & 136.0 \\
\cline { 2 - 9 } & 3-S10F10R10 & 12.1 & 2057 & 7.31 & 98.2 & 9.2 & 0.22 & 111.6 \\
\cline { 2 - 9 } & 3-S20R10 & 14.3 & 2024 & 4.46 & 96.6 & 10.2 & 0.07 & 123.3 \\
\hline
\end{tabular}

On the other hand, significant differences of the mixtures in relative values have been found according to water absorption values. The following can be highlighted:

- All the mortars with waste materials show higher absorption values than the control sample, reaching relative values of up to $136 \%$ (mortar 3-S30). If the waste materials are ordered from higher to lower absorption, according to the results of series S1: SSA, MD, RHA, FA, it shows that the classification is kept, with the same order than in density.

- The different combinations of waste materials on series S2 and S3 show similar behavior than the previous classification; e.g.1, mortar 2-S10M10 shows higher absorption values than mortar 2-S20; e.g.2, mortars with FA show that this residue compensates the effect of others, as it can be observed in mixtures 2-M10F10 y 3-S10F10R10, and this could be due to a lubricant effect of the FA particles that allows a better compaction.

As expected [32], the correlation between both variables is confirmed in the correlation matrix (section 3.5). A regression graph was performed to complete the statistical analysis (Figure 3). It includes all the mixtures of the series and shows that the relation between the selected variables is statistically significant $(\mathrm{P}$-value in Anova table $=0.000<0.05)$ and relatively strong (Coef. $0.955)$ with a negative value: when the density increases the mortar's absorption decreases.

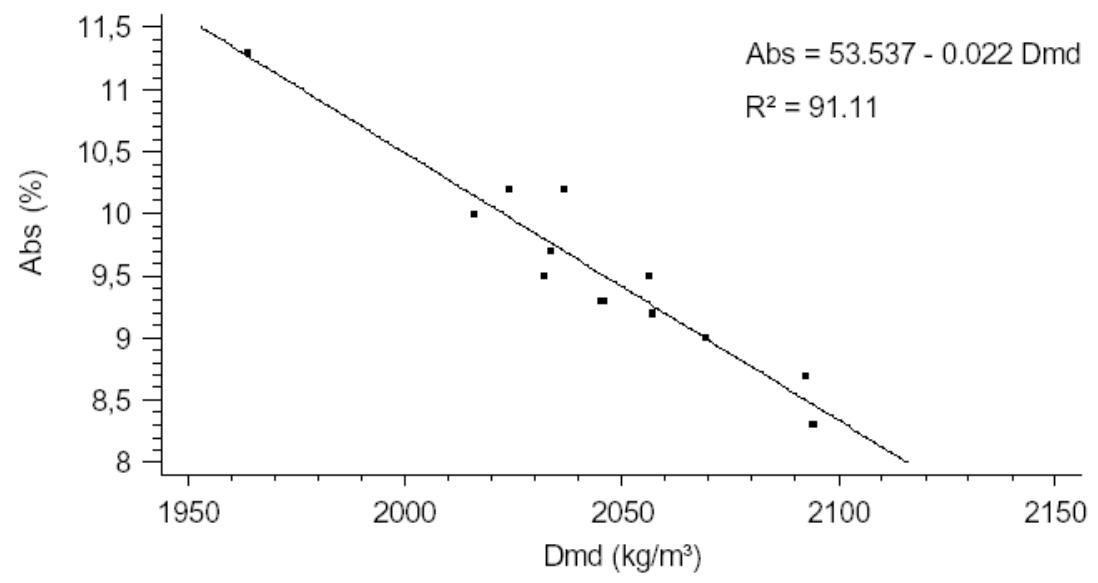

Figure 3. Mortar. Graph of the adjusted model. Relation between density and absorption in specimens cured for 90 days.

\subsection{Mechanical strengths in mortars}


In this section the mean values of compressive (Rc) strengths of representative mortars from each set, as well as the ultrasonic pulse velocity (Upv) results at 28 and 90 days of curing time will be presented. These data are summarized in Tables 7, 8 and 9 .

Table 7. Mortar - Series S1. Rc and Upv values in specimens cured for 28 and 90 days. ( $\sigma$ : standard deviation, rel: relative value respect to control sample)

\begin{tabular}{|l|ccc|ccc|}
\hline $\begin{array}{c}\text { Reference } \\
\text { sample }\end{array}$ & $\begin{array}{c}R c \\
(\mathrm{MPa})\end{array}$ & $\begin{array}{c}\sigma \\
(\mathrm{MPa})\end{array}$ & $\begin{array}{c}\text { rel. } \\
(\%)\end{array}$ & $\begin{array}{c}\text { Upv } \\
(\mathrm{km} / \mathrm{s})\end{array}$ & $\begin{array}{c}\sigma \\
(\mathrm{km} / \mathrm{s})\end{array}$ & $\begin{array}{c}U p v \\
\text { rel. } \\
(\%)\end{array}$ \\
\hline $\mathrm{C}-28$ & 38.0 & 1.2 & 100 & & & \\
$\mathrm{C}-90$ & 41.1 & 1.4 & 100 & 4.25 & 0.03 & 100 \\
\hline $1-\mathrm{S} 10-28$ & 33.5 & 2.2 & 88.1 & & & \\
$1-\mathrm{S} 10-90$ & 35.0 & 1.2 & 85.2 & 3.96 & 0.01 & 93.3 \\
\hline $1-\mathrm{R} 10-28$ & 37.5 & 2.1 & 98.8 & & & \\
$1-\mathrm{R} 10-90$ & 44.4 & 1.1 & 107.9 & 4.20 & 0.02 & 98.8 \\
\hline $1-\mathrm{M} 10-28$ & 27.9 & 1.0 & 73.4 & & & \\
$1-\mathrm{M} 10-90$ & 28.5 & 1.5 & 69.3 & 3.88 & 0.01 & 91.3 \\
\hline $1-\mathrm{F} 10-28$ & 33.5 & 1.3 & 88.0 & & & \\
$1-\mathrm{F} 10-90$ & 37.8 & 2.6 & 92.0 & 4.05 & 0.03 & 95.3 \\
\hline
\end{tabular}

Table 8. Mortar - Series S2. Rc and Upv values in specimens cured for 28 and 90 days. ( $\sigma$ : standard deviation, rel: relative value respect to control sample).

\begin{tabular}{|l|ccc|ccc|}
\hline \multicolumn{1}{|c|}{$\begin{array}{c}\text { Reference } \\
\text { sample }\end{array}$} & $\begin{array}{c}R c \\
(\mathrm{MPa})\end{array}$ & $\begin{array}{c}\sigma \mathrm{MPa}) \\
\text { rel. } \\
(\%)\end{array}$ & $\begin{array}{c}\text { Upv } \\
(\mathrm{km} / \mathrm{s})\end{array}$ & $\begin{array}{c}\sigma \\
(\mathrm{km} / \mathrm{s})\end{array}$ & $\begin{array}{c}\text { Upv } \\
\text { rel. } \\
(\%)\end{array}$ \\
\hline C-28 & 38.0 & 1.2 & 100 & & & \\
C-90 & 41.1 & 1.4 & 100 & 4.25 & 0.03 & 100 \\
\hline 2-S20-28 & 31.9 & 1.1 & 83.8 & & & \\
2-S20-90 & 32.3 & 0.6 & 78.5 & 3.99 & 0.02 & 93.9 \\
\hline 2-S10F10-28 & 31.8 & 1.9 & 83.7 & & & \\
2-S10F10-90 & 34.8 & 1.8 & 84.7 & 4.02 & 0.02 & 94.6 \\
\hline 2-S10M10-28 & 30.1 & 1.1 & 79.2 & & & \\
2-S10M10-90 & 31.2 & 0.7 & 75.8 & 3.83 & 0.02 & 90.1 \\
\hline 2-M10F10-28 & 28.8 & 0.5 & 75.9 & & & \\
2-M10F10-90 & 31.3 & 1.6 & 76.1 & 3.97 & 0.02 & 93.5 \\
\hline 2-S10R10-28 & 34.2 & 0.7 & 90.0 & & & \\
2-S10R10-90 & 37.5 & 2.4 & 91.3 & 4.17 & 0.02 & 98.3 \\
\hline
\end{tabular}

Table 9. Mortar - Series S3. Rc and Upv values in specimens cured for 28 and 90 days. $(\sigma$ : standard deviation, rel: relative value respect to control sample)

\begin{tabular}{|l|ccc|ccc|}
\hline $\begin{array}{c}\text { Reference } \\
\text { sample }\end{array}$ & $\begin{array}{c}R c \\
(\mathrm{MPa})\end{array}$ & $\begin{array}{c}\sigma \\
(\mathrm{MPa})\end{array}$ & $\begin{array}{c}R c \\
\text { rel. } \\
(\%)\end{array}$ & $\begin{array}{ccccc}\text { Upv } \\
(\mathrm{km} / \mathrm{s})\end{array}$ & $\begin{array}{c}\sigma \\
(\mathrm{km} / \mathrm{s})\end{array}$ & $\begin{array}{c}\text { Upv } \\
\text { rel. }\end{array}$ \\
\hline C-28 & 38.0 & 1.2 & 100 & & & \\
C-90 & 41.1 & 1.4 & 100 & 4.25 & 0.03 & 100 \\
\hline 3-S30-28 & 23.5 & 1.4 & 61.9 & & & \\
3-S30-90 & 24.4 & 2.3 & 59.3 & 3.88 & 0.02 & 91.3 \\
\hline 3-S10F10R10-28 & 33.6 & 0.9 & 88.4 & & & \\
3-S10F10R10-90 & 45.0 & 1.7 & 109.4 & 4.20 & 0.03 & 99.0 \\
\hline
\end{tabular}




\begin{tabular}{|l|ccc|ccc|}
\hline $\begin{array}{c}\text { Reference } \\
\text { sample }\end{array}$ & $\begin{array}{c}R c \\
(\mathrm{MPa})\end{array}$ & $\begin{array}{c}\sigma \mathrm{MPa}) \\
(\%)\end{array}$ & $\begin{array}{c}\text { rel. } \\
(\%)\end{array}$ & $\begin{array}{c}\text { Upv } \\
(\mathrm{km} / \mathrm{s})\end{array}$ & $\begin{array}{c}\sigma \\
(\mathrm{km} / \mathrm{s})\end{array}$ & $\begin{array}{c}\text { rel. } \\
(\%)\end{array}$ \\
\hline 3-S20R10-28 & 34.0 & 1.8 & 89.5 & & & \\
3-S20R10-90 & 38.2 & 1.9 & 92.8 & 4.15 & 0.02 & 97.7 \\
\hline
\end{tabular}

The following considerations can be established regarding the compressive strength (Rc), whose results are shown in tables 7, 8 and 9 and in Figure 4:

- The Rc values increase positively with the curing time in all cases: average increases ranging from $10 \%$ in $\mathrm{S} 1$ series, $7 \%$ in the $\mathrm{S} 2$ series, and $16 \%$ in $\mathrm{S} 3$ series.

- In general, the Rc values of the specimens analyzed are lower than the values of the control sample for the two curing ages, with the only exception of mixtures 1-R10 and 3$\mathrm{S} 10 \mathrm{~F} 10 \mathrm{R} 10$ in which the Rc values are higher than in the control sample. This behavior is directly related to the high pozzolanic reactivity of RHA. In the case of mortar 3S10F10R10, with $30 \%$ replacement of cement, the combination of three wastes let to have a very good mechanical performance.

- Almost all the mixes show values close to the nominal strength of the cement used (32.5 $\mathrm{MPa}$ ), with the exception of 1-M10, 2-S10M10, 2-M10F10 (containing MD) and 3-S30.

- For the reference series (C, 1-S10, 2-S20 and 3-S30), at higher contents of SSA, lower Rc values were found, with a decrease of nearly $41 \%$ as compared to the control sample for substitutions of $30 \%$.

- The good results obtained from using RHA and FA individually in series S1, are also reflected when combining them in binary or ternary blends with the other two residues (SSA y MD) in the other two series (S2 and S3).




Figure 4. Mortar. Compressive strength. Average absolute values of the specimens with curing ages of 28 and 90 days.

From the Upv test results in specimens cured for 90 days, it follows that the relative values of the mixes are in a range from 90 to $99 \%$ of the control sample (see Tables 7, 8 and 9). Finally, according to the matrix in section 3.5, it can be stated that there is a correlation between Rc and Upv, and as a consequence of this the statistical analysis is extended with the corresponding linear regression graph (Figure 5), which includes all the mixtures of the series. This figure shows for all the mortars analyzed that the compressive strength increases as the Upv increases.

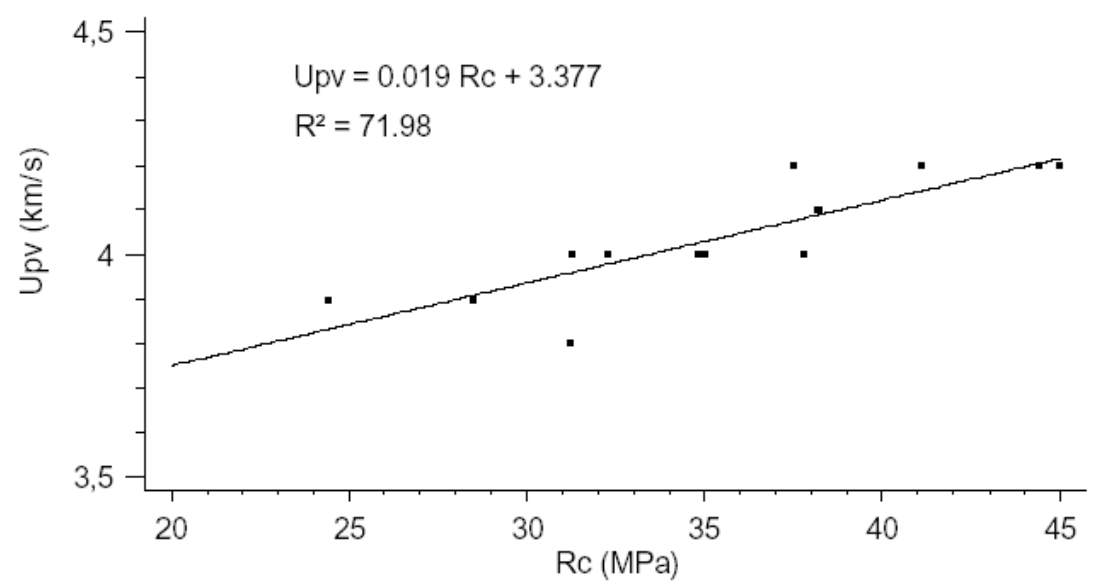

Figure 5. Mortar. Graph of the adjusted model. Relation between compressive strength and ultrasonic pulse velocity in specimens cured for 90 days.

The relationship obtained between both variables (Rc and Upv), which according to its coefficient $(0.848$ - see Table 11$)$ is moderately strong, is reduced by the existence of two atypical residues, or what is the same, observations with studentized residuals greater than 2 in absolute value, but none greater than 3 . This is a measure of how many standard shifts each value of Upv from the adjusted model, using all the data, except that observation. If it were greater than 3 , these observations should be examined carefully to determine whether they are irrational values that should be removed from the model and treated separately. If we consider the observation of mortar 2-S10M10 as an irrational result and it is removed from the model, for being in the limit set, the correlation coefficient increases up to 0.892 with a P-value $=0.000$, approaching the relatively strong rating.

\subsection{Correlation matrix}

A multivariable analysis is carried out, including all samples of pastes and mortars. The results have been summarized in tables 10 and 11 . According to the codification of the variables, the next format was followed:

$$
\text { System (P, M)_Variable (parameter's acronym)_curing age (7d, 28d, 90d) }
$$

using for this: in the System, the initials of the cementitious matrix (paste or mortar); in the Variable, the acronym to identify as variables the different parameters, which coincide with the ones used throughout this paper (FP: \% fixed portlandite, Dmd: dry mass density, Abs: water absorption, Rc: compressive strength, Upv: ultrasonic pulse velocity) and the curing age of 7, 28 or 90 days, as the case may be.

Table 10 includes measures of central tendency, variability and form. Each one of the 13 analyzed data, one for each series, is represented by one sample for pastes and by the mean value of three samples for mortars. Of particular interest are those which can be used to 
determine if the sample is away from a normal distribution (Gaussian distribution): it can be seen that all the variables have skewness values and standardized kurtosis in the range of -2 to +2 , which indicates that there are no significant deviations from normal.

Table 10. Statistical summary.

\begin{tabular}{|c|c|c|c|c|c|c|c|c|}
\hline Statistic & $\begin{array}{c}P_{-} F P \\
7 d\end{array}$ & $\begin{array}{c}P_{-} F P \\
28 d\end{array}$ & $\begin{array}{l}P_{-} F P \\
90 d\end{array}$ & $\begin{array}{c}M_{-} \text {Dmd } \\
90 d\end{array}$ & $\begin{array}{c}M \_A b s \\
90 d\end{array}$ & $\begin{array}{c}M \_R c \\
28 d\end{array}$ & $\begin{array}{c}M_{-} R c \\
90 d\end{array}$ & $\begin{array}{c}M_{-} U p v \\
90 d\end{array}$ \\
\hline Count & 13 & 13 & 13 & 13 & 13 & 13 & 13 & 13 \\
\hline Average & 14.1 & 22.4 & 34.2 & 2043.6 & 9.6 & 32.2 & 35.5 & 4.0 \\
\hline $\begin{array}{l}\text { Standard } \\
\text { deviation }\end{array}$ & 15.3 & 23.0 & 29.3 & 33.8 & 0.8 & 3.9 & 6.0 & 0.1 \\
\hline $\begin{array}{c}\text { Coef. } \\
\text { Variation }(\%)\end{array}$ & 108.1 & 102.3 & 85.6 & 1.7 & 8.0 & 12.2 & 17.0 & 3.2 \\
\hline Minimum & -2.2 & -5.2 & -1.3 & 1963.9 & 8.3 & 23.5 & 24.4 & 3.8 \\
\hline Maximum & 39.4 & 63.0 & 83.4 & 2094.1 & 11.3 & 38.0 & 45.0 & 4.2 \\
\hline Range & 41.6 & 68.2 & 84.7 & 130.2 & 3.0 & 14.5 & 20.6 & 0.4 \\
\hline $\begin{array}{c}\text { Standardized } \\
\text { skewness }\end{array}$ & 0.7 & 0.9 & 1.0 & -1.0 & 1.0 & $-1, .0$ & -0.1 & -0.1 \\
\hline $\begin{array}{c}\text { Standardized } \\
\text { kurtosis }\end{array}$ & -1.0 & -0.7 & -0.6 & 1.3 & 1.0 & 0.6 & -0.3 & -0.7 \\
\hline
\end{tabular}

In Table 11, each pair of variables is related in duplicate, one on the diagonal and the other one below it. In each cell are two values: a) the upper value indicates the Pearson product-moment correlation between each pair of variables. The range of these correlations coefficients is from 1 to +1 , and measures the strength of the linear relationship between variables, which is greater when the coefficients are closer to these values; and b) the lower value is a P-value from the Anova analysis (analysis of variance), which tests the statistical significance of the estimated correlations. P-values below 0.05 indicate correlations significantly different from zero, with a confidence level of $95.0 \%$.

Table 11. Correlation matrix.

\begin{tabular}{|l|c|c|c|c|c|c|c|c|}
\hline & $P_{-} F P$ & $P_{-} F P$ & $P_{-} F P$ & $M_{-} D m d$ & $M_{-} A b s$ & $M_{-} R c$ & $M_{-} R c$ & $M_{-} U p v$ \\
& $7 d$ & $28 d$ & $90 d$ & $90 d$ & $90 d$ & $28 d$ & $90 d$ & $90 d$ \\
\hline$P_{-} F P$ & & 0.9509 & 0.8562 & -0.6380 & 0.7034 & -0.1142 & -0.0482 & 0.1775 \\
$7 d$ & & 0.0000 & 0.0002 & 0.0190 & 0.0073 & 0.7102 & 0.8759 & 0.5617 \\
\hline$P_{-} F P$ & 0.9509 & & 0.9642 & -0.4802 & 0.5807 & 0.0371 & 0.1904 & 0.3552 \\
$28 d$ & 0.0000 & & 0.0000 & 0.0967 & 0.0374 & 0.9043 & 0.5333 & 0.2337 \\
\hline$P \_F P$ & 0.8562 & 0.9642 & & -0.3248 & 0.4496 & 0.1172 & 0.3220 & 0.4591 \\
$90 d$ & 0.0002 & 0.0000 & & 0.2790 & 0.1232 & 0.7030 & 0.2833 & 0.1146 \\
\hline$M_{-} D m d$ & -0.6380 & -0.4802 & -0.3248 & & -0.9545 & 0.7226 & 0.6777 & 0.5183 \\
$90 d$ & 0.0190 & 0.0967 & 0.2790 & & 0.0000 & 0.0053 & 0.0109 & 0.0696 \\
\hline$M_{-} A b s$ & 0.7034 & 0.5807 & 0.4496 & -0.9545 & & -0.6661 & -0.6027 & -0.3934 \\
$90 d$ & 0.0073 & 0.0374 & 0.1232 & 0.0000 & & 0.0129 & 0.0292 & 0.1835 \\
\hline$M_{-} R c$ & -0.1142 & 0.0371 & 0.1172 & 0.7226 & -0.6661 & & 0.8991 & 0.7712 \\
$28 d$ & 0.7102 & 0.9043 & 0.7030 & 0.0053 & 0.0129 & & 0.0000 & 0.0020 \\
\hline$M_{-} R c$ & -0.0482 & 0.1904 & 0.3220 & 0.6777 & -0.6027 & 0.8991 & & 0.8484 \\
$90 d$ & 0.8759 & 0.5333 & 0.2833 & 0.0109 & 0.0292 & 0.0000 & & 0.0002 \\
\hline$M_{-} U p v$ & 0.1775 & 0.3552 & 0.4591 & 0.5183 & -0.3934 & 0.7712 & 0.8484 & \\
$90 d$ & 0.5617 & 0.2337 & 0.1146 & 0.0696 & 0.1835 & 0.0020 & 0.0002 & \\
\hline
\end{tabular}


The matrix of Table 11 emphasizes the correlation coefficients between the same variables at different ages, and the existing relations between: density - absorption, density - compressive strength - ultrasonic pulse velocity, all of them present in mortars. Based on these results, the analysis is completed with the realization of simple regression models, already included in previous sections.

\section{CONCLUSIONS}

According to data analyzed in this research, the following conclusions can be established:

The pozzolanic effect of the different mineral admixtures used in this research is verified even at early ages. A rapid consumption of CA compared to FA (at 7 days) was observed when SSA was the only admixture, but it was limited to a longer-term basis compared to RHA (at 90 days).Their different degrees of activity, from the inert MD to the highly reactive RHA, have been reflected in their combinations for the different tests carried out. In pastes with high percentages of mineral admixtures occurs a high reduction of the remaining $\mathrm{CH}$ (in some cases more than $50 \%$ of fixed portlandite).

The partial substitution of Portland cement in mortars, by binary and ternary combinations of waste materials, implies:

a) Physical characteristics: in general, the densities are similar but the water absorptions are higher when compared to control samples. Although this, some combinations of waste materials can improve this characteristic, mainly the ones containing FA.

b) Mechanical strengths: most of the mixes show similar or higher compressive strengths than the strength class of the cement used (32.5 MPa). The apparent pozzolanic activity when SSA was the only admixture did not entail higher compression strength than the control sample. Nevertheless the use of RHA in combination with SSA or in combination with SSA/FA, by replacing $30 \%$ of cement, let to obtain better mechanical performance than those obtained with plain cement.

c) Finally it should be noted that there is a correlation that can be qualified as strong between density and absorption in mortars: when Dmd decreases Abs increases. This correlation is similar to the relatively strong correlation between ultrasonic pulse velocity and compressive strength that increases when increasing Upv.

\section{REFERENCES}

[1] Center for Studies and Experimentation of Public Works (CEDEX) - Ministerio de Fomento. Usable Waste Catalogue under Construction. <http://www.cedex.es> [accessed May 2013].

[2] AENOR. UNE-EN 197-1. Cement. Part 1: Composition, specifications and conformity criteria for common cements. 2000.

[3] Alam J, Akhtar MN. Fly ash utilization in different sectors in Indian scenario. Int J Emerg Trends Eng Develop 2011;1,1:1-14.

[4] <http://minerals.er.usgs.gov/minerals/pubs/commodity/iron_\&_steel_slag/islagmyb02.pdf> [accessed May 2014].

[5] European Commission. Environmental, economic and social impacts of the use of sewage sludge on land. In: Final Report. Part I: Overview Report, 2010, p. 3-8.

[6] Ministerio de Agricultura, Alimentación y Medio Ambiente. $<$ http://www.magrama.gob.es/es/calidad-y-evaluacion-ambiental/temas/prevencion-y-gestionresiduos/flujos/lodos-dep> [accessed May 2013]. 
[7] Cyr M, Coutand M, Clastres P. Technological and environmental behaviour of sewage sludge ash (SSA) in cement-based materials. Cem Concr Res 2007;37:1276-89.

[8] Lapa N, Barbosa R, Lopes MH, Mendes B, Abelha P, Gulyurtlu I, Oliveira JS. Chemical and ecotoxicological characterization of ashes obtained from sewage sludge combustion in a fluidised-bed reactor. J Haz Mat 2007;147 (1-2):175-83.

[9] Donatello S, Tyrer M, Cheeseman CR. EU landfill waste acceptance criteria and EU hazardous waste directive compliance testing of incinerated sewage sludge ash. Waste Man 2010;30:63-71.

[10] Asociación Mármol de Alicante. <http://www.marmoldealicante.es> [accessed July 2013].

[11] Monzó J, Payá J, Borrachero MV, Córcoles A. Use of sewage sludge ash (SSA)-cement admixtures in mortars. Cem Concr Res 1996;26:1389-98.

[12] Alcocel EG, Garcés P, Martinez JJ, Payá J, Garcia L. Effect of sewage sludge ash (SSA) on the mechanical performance and corrosion levels of reinforced Portland cement mortars. Mater Construcc 2006; 56: 31-43.

[13] Payá J, Monzó J, Borrachero MV, Amahjour F, Girbés I, Velázquez S, Ordóñez LM. Advantages in the use of fly ashes in cements containing pozzolanic combustion residues: silica fume, sewage sludge ash, spent fluidized bed catalyst and rice husk ash. J Chem Technol Biot 2002;77:331-5.

[14] Donatello S, Tyrer S, Cheeseman CR. Comparison of test methods to assess pozzolanic activity. Cem Concr Comp 2010;32:121-7.

[15] GIQUIMA. Proyecto PEL-CEN. <http://epsar.cop.gva.es/depuradorasv> [accessed July 2013].

[16] Gonçalves A, Esteves AM, Carvalho M, Machado A, Correia E. Incorporation of sludge from a water treatment plant in cement mortars. In: International RILEM Conference on the Use of Recycled Materials in Buildings and Structures, Barcelona, Spain; 2004.

[17] Malhotra VM, Ramezanianpour AA. Fly Ash in Concrete. In: CANMET, Canada Center for Mineral and Energy Technology, Natural Resources Canada, Ottawa, Ontario, Canada; 1994.

[18] Peris E, Payá J, Monzó J. Influence of different sized fractions of a fly ash on workability of mortars. Cem Concr Res 1993;23:917-24.

[19] Monzó J, Borrachero MV, Payá J, Girbés I. Morteros de cementos compuestos a base de cenizas volantes de central termoeléctrica de carbón (CV) y cenizas procedentes de la incineración de lodos de depuradora (CLD). In: Proceedings of the III Congreso Nacional de Materiales Compuestos, Benalmádena-Málaga, Spain; 1999. p. 477-83.

[20] Borrachero MV, Payá J, Monzó J, Bonilla M, Girbés I. Evolución de las resistencias mecánicas de sistemas ternarios cemento/ceniza volante/ceniza de lodo de depuradora: efectos puzolánicos complementarios. In: Proceedings of the PMS2002 VIII Congreso Nacional de Propiedades Mecánicas de Sólidos, Gandía-Valencia, Spain; 2002. p. 601-9.

[21] Corinaldesi V, Moriconi G, Naik TR. Characterization of marble powder for its use in mortar and concrete. Constr Build Mater 2010;24:113-7.

[22] Binici H, Kaplan H, Yilmaz S. Influence of marble and limestone dusts as additives on some mechanical properties of concrete. Scient Res Ess 2007;9:372-9.

[23] Valdez P, Barragán B, Girbés I, Shuttleworth N, Cockburn A. Use of waste from the marble industry as filler for the production of self-compacting concrete. Mater Construcc 2010; 61: 61-76.

[24] Khana R, Jabbara A, Ahmada I, Khana W, Khana AN, Mirzab J. Reduction in environmental problems using rice-husk ash in concrete. Constr Build Mater 2012;30:360-5.

[25] Madandoust R, Ranjbar MM, Moghadam HA, Mousavi SY. Mechanical properties and durability assessment of rice husk ash concrete. Bios Eng 2011;110:144-52.

[26] AENOR. UNE-EN 196-1. Methods of testing cement. Part 1: Determination of strength. 2005.

[27] Payá J, Monzó J, Borrachero MV, Velázquez S. Evaluation of the pozzolanic activity of fluid catalytic cracking catalyst residue (FC3R). Thermogravimetric analysis studies on FC3RPortland cement pastes. Cem Concr Res 2003;33:603-9. 
[28] AENOR. UNE-EN 1015-3. Methods of test for mortar for masonry. Part 3: Determination of consistence of fresh mortar (by flow table). 2000.

[29] AENOR. UNE-EN 1015-10. Methods of test for mortar for masonry. Part 10: Determination of dry bulk density of hardened mortar. 2000.

[30] Garcés P, Pérez Carrión M, García-Alcocel E, Payá J, Monzó J, Borrachero MV. Mechanical and physical properties of cement blended with sewage sludge ash. Waste Man 2008;28(12):2495-502.

[31] AENOR. UNE-EN 1015-10:2000/A1. Methods of test for mortar for masonry. Part 10: Determination of dry bulk density of hardened mortar. 2007.

[32] BS EN ISO 10545-3. Ceramic tiles. Part 3: determination of water absorption, apparent porosity, apparent relative density and bulk density. 1997. 